\title{
Collaborative Robots in a Human-Centered Assembly System
}

\author{
Åsa Fast-Berglund* \\ Chalmers University of Technology, Sweden
}

Submission: February 13, 2018; Published: April 25, 2018

*Corresponding author: Åsa Fast-Berglund, Chalmers University of Technology, Sweden, SE-41296, Tel: +46317723686;

Email: asa.fasth@chalmers.se

\begin{abstract}
This paper offers a brief overview of collaborative robots and the importance of Design for automated assembly. This means to not only design the assembly stations with user friendly cobots but also to analyze and improve the product towards higher physical level of automation in assembly systems.
\end{abstract}

Keywords: Collaborative robots; Design for Automated Assembly; Assembly systems; Human-centered

\section{Introduction}

Human-centered assembly systems can be describe as a system designed to interact with people intelligently [1]. Collaborative robots is getting more and more common as a solution to increase the level of automation in production and assembly systems [2]. Case-studies conducted in Sweden shows that over 90 percent of assembly systems still are manual [3], the cobots could be a solution in order to decrease this percent and to get more cobots into assembly stations. In cases where the robots are installed it is more co-existing than collaborative, but there are some solutions towards a collaborative environment [4-6]. In order to get truly collaborative workstations, the robot and the operator needs to share both the station and the work piece according to the standard ISO/TS 15066:2016. Today a lot of the solutions are technology driven towards cyber physical systems and different virtual tolls, such as augmented reality. Hence, in order to achieve collaborative work stations, well designed products for automation is vital in order to create a well functional collaborative work station.

Design for Automated Assembly (DFAA)

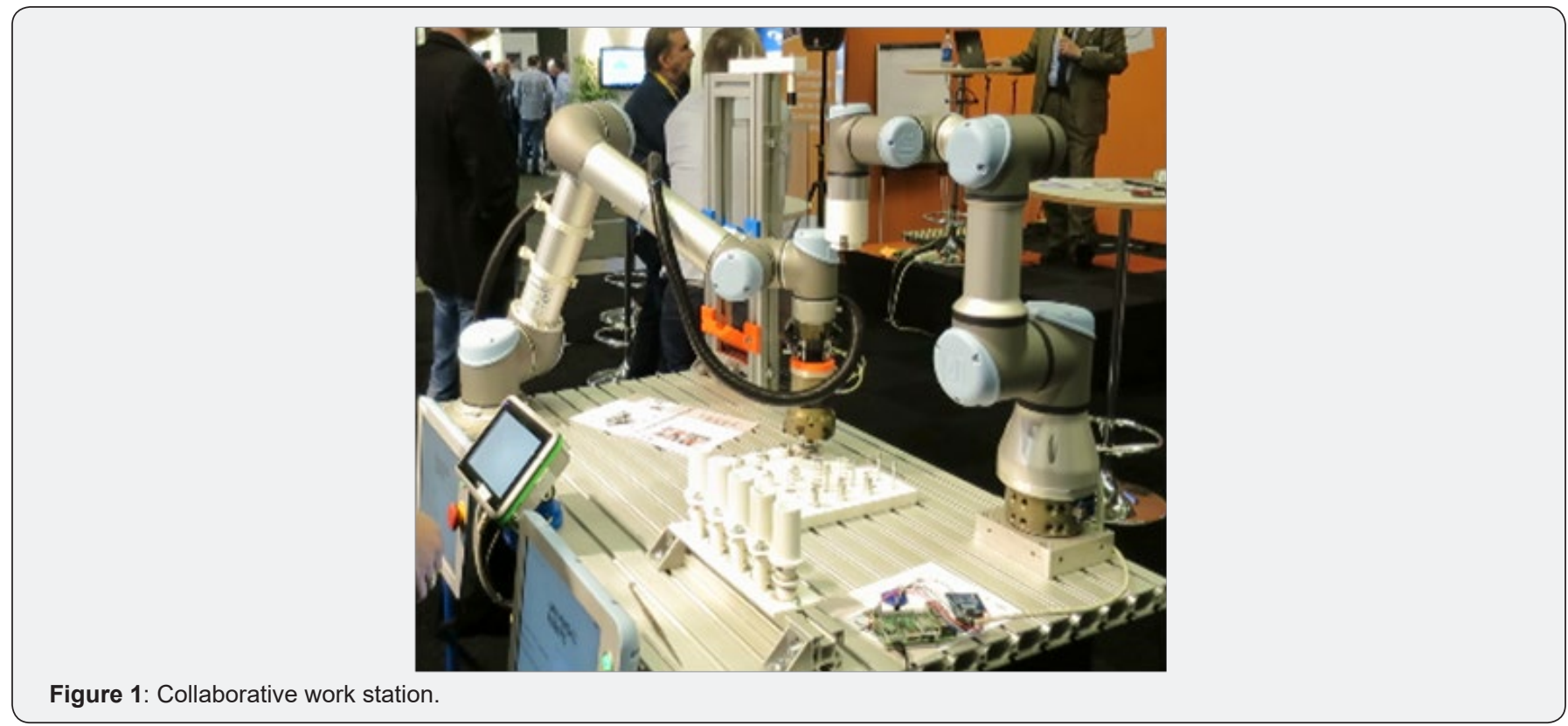




\section{Robotics \& Automation Engineering Journal}

An important step towards an increased level of physical automation is to design the products for automated stations. One method is DFA(A), this method was first published over twenty years ago The idea is to reduce the manufacturing cost such that the design eases manufacture of the parts making up the complete product without compromising quality of the final product [7]. Even though, product cost savings between $15 \%$ and $70 \%$ have resulted from analysis and redesign [8] using DFA-analysis not many companies uses this method in Sweden. DFAA provides a clear picture of which components and tasks should be prioritized to increase automation and could be divided into two main levels, product level and component level [9]. An industrial case study performed in final assembly aimed to increase automation [6] also showed a possible improvement of almost 70 percent on the product level, using DFAA-analysis. The main improvement was to decide a component to be a main base object and to design fixtures. Fixtures are very important in order to increase automation in a system [10] and flexible fixturing [11] can enable an adaptable fixture to be used in a mass customized systems, which the assembly system often is. The fixtures should be designed for the main product but also for the components, in order to be kitted and easily handled by the cobot. On a component level, the main improvement was also fixturing and sorting of components. A time-saving of 68 percent per product i.e. $266.8 \mathrm{sec} \sim 4.5 \mathrm{~min} /$ product. If the company produces 10000 products $/$ year $=750 \mathrm{~h}=18$ weeks $=$ 600000 SEK (if the salary for the operator is $800 \mathrm{sek} / \mathrm{h}$ ). The automated station illustrated in Figure 1 costs around 500 000 SEK, which means that RoI of this stations is less than 18 weeks.

The assembly fixtures and component fixtures were 3D printed as a first step. The operator and the robot is sharing the component fixture, but it is also possible to share the assembly fixture as well. This means that the station can be defined as a truly collaborative work station.

\section{Conclusion}

In order to increase the usage of cobots in a humancentered assembly system, the usage of a method such as DFAA needs to be further developed in order to increase automation in final assembly. When the allocation between humans and automation is decided, collaborative work stations can be designed. This paper has presented some thoughts about the need for a standardization and product design for automated assembly systems. Cobots is one solution towards an increase of levels of automation in assembly systems but the product design might be as important as the safety and user-friendly and collaborative robots.

\section{References}

1. Dorais GA, Bonasso RP, Kortenkamp D, Pell B, Schreckenghost D (1998) Adjustable Autonomy for Human-Centered Autonomous Systems.

2. Paxton C, Hundt A, Jonathan F, Guerin K, Hager GD (2017) CoSTAR: Instructing collaborative robots with behavior trees and vision. In 2017 IEEE International Conference on Robotics and Automation (ICRA), pp. 564-571.

3. Fasth-Berglund $\AA$, Stahre J (2013) Cognitive automation strategy for reconfigurable and sustainable assembly systems. Assembly Automation 33: 294-303.

4. Maurice P, Padois V, Measson Y, Bidaud P (2017) Human-oriented design of collaborative robots. International Journal of Industrial Ergonomics 57: 88-102.

5. Wang XV, Kemény Z, Váncza J, Wang L (2017) Human-robot collaborative assembly in cyber-physical production: Classification framework and implementation. CIRP Annals 66(1): 5-8.

6. Fast-Berglund Å, Palmkvist F, Nyqvist P, Ekered S, Åkerman M (2016) Evaluating Cobots for Final Assembly. Procedia CIRP 44: 175-180.

7. Synnes EL, Welo T (2015) Design for Automated Assembly of Large and Complex Products: Experiences from a Marine Company Operating in Norway. Procedia Computer Science 44: 254-265.

8. PJ S, AEK H (1988) DFA as a primary process decreases design deficiencies. Assembly Automation 8: 137-140.

9. Fast-Berglund Å, Mattsson S (2017) Smart Automation - metoder för slutmontering.

10. Trappey JC, Liu CR (1990) A literature survey of fixture design automation. The International Journal of Advanced Manufacturing Technology 5(3): 240-255.

11. Bi ZM, Zhang WJ (2001) Flexible fixture design and automation: Review, issues and future directions. International Journal of Production Research 39: 2867-2894.

\section{Your next submission with Juniper Publishers will reach you the below assets}

Commons Attribution 4.0 License

DOI: 10.19080/RAEJ.2018.02.555600 